\title{
Being seconded to a Mental Health Trust: the (in)visibility of mental health social work
}

\begin{abstract}
The paper explores the implications of being a social worker seconded to a Mental Health Trust based on narrative interviews with mental health social workers. As part of a wider study, thirteen mental health social workers from across England were interviewed individually about their experiences of being seconded to a Mental Health Trust. Building on the work of Andrew Pithouse, the findings reveal the (in)visibility of mental health social work. The social workers were isolated within Health Trusts with minimal links to their Local Authority employers. They struggled to articulate and define social work. Instead, social work was depicted as being indefinable, involving working in liminal spaces and as filling the gaps left by other professions. Furthermore, the social workers were unable to make social work visible as social work is not 'seen' by the other members of the team. Finally, the social workers were unable to make social visible through supervision if they did not have a social work manager. The paper ends with an unexpected outcome of the research: the notion of the research interview as surrogate supervision.
\end{abstract}

Keywords: Approved Mental Health Professional, mental health, supervision.

\section{Introduction}

In the last decade, mental health social workers have experienced a great deal of change in their working practices. Originally based in Social Services Departments within a Local Authority with other social workers, many mental health social workers (MHSWs) in the statutory sector have been separated from other social workers and are now based in Mental Health Trusts with health professionals. There may be only one or two social workers in any one mental health team. As part of a wider study exploring social work identity (Morriss, 2014), thirteen MHSWs seconded to Mental Health Trusts were interviewed using a dialogical narrative approach (Riessman, 2007). Building on the notion of social work as an 'invisible trade' (Pithouse, 1984; 1998), the paper will discuss the isolation of being a social worker in a Mental Health Trust. Leading on from this, there will be a discussion about supervision arrangements within the Trusts. Finally, the idea of the research interview as surrogate supervision will be explored. 


\section{Social work as an invisible trade}

Andrew Pithouse $(1984 ; 1998)$ contended that social work is an 'invisible trade'. Drawing on symbolic interactionism and ethnomethodology, Pithouse (1984) argued that social work is 'invisible' in three particular ways: first, the majority of social work practice with service users is unobserved by colleagues or managers; secondly, the outcomes of social work intervention are uncertain and ambiguous; and thirdly, social work practitioners rely upon rarely stated motives and taken for granted assumptions in order to accomplish their daily work (Pithouse, 1998 p.4-5). For Pithouse (1998, p.178) social work is accomplished in the setting; made visible through talk with social work colleagues and in supervision with social work managers. Pithouse (1998 p.5) concluded that 'social work is invisible...only those who are accustomed to the occupational experience can appreciate what it means to do social work'.

Significantly, the children and family social workers in Pithouse's study were based in the Local Authority. Thus, they were situated with social work colleagues and social work managers which meant there was a 'shared frame of reference' (Pithouse, 1998 p.165). In contrast, thirteen of the social workers in my project were separated from other social workers and situated with health professionals and thus this 'shared frame of reference' does not exist. If social work is an invisible trade and only made visible through collegiate relationships and in supervisory encounters as Pithouse (1984) has argued, how then can it be made visible where there may not be other social workers in the team? These questions will be explored in the paper.

\section{Method}

The empirical work presented here is taken from a wider ESRC funded doctoral study exploring the identity of social work Approved Mental Health Professionals (AMHPs) seconded to Mental Health Trusts (Morriss, 2014). The study was approved by the University of Salford's Research Ethics Panel (REP11/067). Using a dialogical narrative approach (Riessman, 2007), seventeen MHSWs from across England were interviewed individually. All were practicing AMHPs who had responded to a Participant Information Sheet circulated via AMHP Leads. The interviews were audio-taped with the consent of the participants, transcribed in full, and fully anonymised. Of the seventeen participants in the 
wider study, thirteen were seconded to Mental Health Trusts. The present paper is focused on the analysis of the interviews with these mental health social workers.

The interviews were analysed using dialogical narrative analysis (Riessman, 2008) and ethnomethodology (Garfinkel, 1967). Unlike the structural and the thematic approaches to narrative, the dialogical approach is concerned with how talk is interactively (dialogically) produced and performed as narrative. From this approach, the researcher is recognised as an active presence and accounts are seen as co-produced:

Investigators carry their identities with them like tortoise shells into the research setting, reflexively interrogating their influences on the production and interpretation of narrative data. (Riessman, 2007 p.139)

Thus, the part played by the interviewer in the dialogue is kept in the excerpts included in the research text.

In line with the analytical approach used by Pithouse, the interviews were also analysed using ethnomethodology. Ethnomethodology was devised by Harold Garfinkel [1917-2011] and is the study of the methods that members use to produce mutually recognisable social interaction. The interaction involves 'work' between members to accomplish a mutually intelligible orderly world. Again, the part played by the interviewer is also subject to analysis. As a registered MHSW with over ten years' practice experience, I was able to understand the specialised vocabulary, institutional talk and indexical expressions (Garfinkel, 1967) in both the on-going practical accomplishment of the interview interaction and in analysis without recourse to a dictionary or a textbook. Thus, I met what Garfinkel (1967) termed the 'unique adequacy requirement of methods'; namely, the requirement to be a competent practitioner of whatever group of participants is being researched (see Morriss, 2015a).

\section{The (in)visibility of mental health social work}

When asked during the interviews, the MHSWs could not readily define mental health social work. They are not alone in this. The Interim Report of the Social Work Taskforce (2009, p.33) concluded that the distinct role of social workers is unclear and that even social 
workers themselves struggle to articulate the central role and purpose of the profession. The social workers in my study were no different. For example, Cath stated:

Cath: It's like the role of social work: what is social work? Before I started I knew it was something valuable but you don't really know you can't label each thing can you? But it can be anything can't it? It can be anything from the most [pause] innocuous thing to the most [pause] [breath] I don't know [pause] traumatic or important or legal or whatever perspective you look at.

Here, as in the Interim Report of the Social Work Task Force, Cath is talking about how difficult it is to define social work, even for a social worker. Even though she has been a qualified social worker for many years, Cath is unable to articulate what social work is or provide a concrete definition. Instead, social work can 'be anything'; and the difficulties of definition can be seen as reflected in the pauses as she attempts to explain. Cath continued:

Cath: It's hard isn't it to say what you've done in a piece of work. I don't know. I think that's probably why social work struggles with its profile isn't it but you can't say. People can't see well I've saved a life because you do sometimes but not in the medical sense.

Again, Cath struggles to explain the social work role. It is interesting that she links this inability to define social work with the negative public profile of social work. Cath's reply endorses Pithouse's description of social work as an invisible trade. The work cannot be seen; in Cath's words, 'you can't say people can't see'. Thus, not only is she unable to articulate what social work is but in addition, social work is not visible to outsiders. The use of the example of saving someone's life can be seen as an 'extreme case formulation' (Pomerantz, 1986); even when social work involves something as immense as saving a life, it is still not visible to other people. Cath then reiterates this point:

Cath: it's really difficult to explain what social work is to someone umm cos you think you just sit and speak to somebody and on the outside that is what it might look like but I suppose it is everything else in the background around the periphery, isn't it?

Cath argues that social work is difficult to define as, to outsiders, doing social work can be seen as simply sitting and talking to someone. For Cath, social work operates in the 
background, at the margins, in ways that are invisible. Again, this resonates with Pithouse's (1998 p.5) depiction of social work: 'only those who are accustomed to the occupational experience can appreciate what it means to do social work'.

Like Cath, Ed positions mental health social work as existing in a liminal space, between the 'underbelly' and the legal, operating within a 'weird kind of area'.

Ed: We really don't have a role. We really don't have a model. Because we sort of operate between the very sort of underbelly of stuff and the legal. There's a really kind of weird kind of area that we operate within and I often think that there isn't a model for us in our society and that is why the perception is so difficult.

For Ed, social work cannot be seen by outsiders due to the lack of a clear societal role or model. Again, this aligns with the notion of social work as an invisible trade; it exists in the margins where it cannot be recognised or seen. Later in the interview, Ed talked about the positive and negative outcomes of not having a clear role:

Ed: But then we have a lot of freedom as well because no-one really I was saying to a friend of mine you know "I can walk into a police station, show my badge and literally walk into someone's cell", you know. We have a lot of freedom to do stuff and that's partially because we are the people who mop up the stuff that other people don't want to do so with that comes with a lot of criticism and the high profile cases.

Here Ed argues that social workers have 'a lot of freedom', a phrase he repeats to emphasise his point. He uses reported speech to voice his own past talk, adding a dramaturgical element, and making his account more vivid (Holt and Clift, 2007). Again, this connects with Pithouse's notion of invisible work; the freedom to undertake work unobserved by others. For Ed, this freedom comes partially from being 'the people who mop up the stuff that other people don't want to do'. Thus, social work is again depicted as liminal; operating in the gaps left by other professions. However, there is a negative side to this freedom. The 'stuff' that other people do not want to do is directly related to the 'criticism and high profile cases' such as the deaths of Peter Connelly, Daniel Pelka and Victoria Climbié. This links with the concept of 'dirty work' introduced by Everett C. Hughes. 
Hughes explained that every occupation contains a bundle of activities, some of which are the 'dirty work' of that group. He defined several ways in which work might be dirty:

It may be simply physically disgusting. It may be a symbol of degradation, something that wounds one's dignity. Finally, it may be dirty work in that it in some way goes counter to more heroic of our moral conceptions. Dirty work of some kind is found in all occupations (Hughes, 1971 p. 343).

Thus, Ed's depiction of MHSW mopping up 'the stuff that other people don't want to do' can be seen as doing the dirty work that other allied professions elude (see Morriss, 2015b).

In line with the other social work interviewees, Eva also talked about this notion of social work as being indefinable, working in liminal spaces and filling in the gaps left by other professions:

Eva: It's a job about so many hats, isn't it? It is quite difficult to say what we do and err perhaps you get the feeling that what we do is paper up the gaps in all the other professionals the bits that are complicated or tricky that's the bits that "oh we'll get the social worker to do that" and that's what we do [laughs]

Eva presents social work as difficult to define, consisting of many different elements. Instead, Eva contends that the role of social work is to 'paper up the gaps' between the roles of other professions by taking on all the more 'complicated or tricky' work. Eva uses reported speech and humour to emphasise her point (Morriss, 2015c). Like Ed, Eva talks about the freedom of being a social worker:

Eva: we have such a lot, we have quite a lot of control over our day to day, how we manage things, as long as we get on with it we're left to it.

Again, Eva's description of being 'left to it' relates to the first point made by Pithouse: MHSWs visit service users in their own homes unobserved by others. They control the work they do with service users; and this work is also not 'visible' to others. There are often no visible outcomes from this work; a service user may become unwell despite any intervention but this is not seen as a negative reflection on any work that the social worker has done. Rather, this is seen as simply the nature of the work. It is only if a service user was to commit suicide or seriously harm someone that the work would be scrutinised by others. 
Thus, this section has described how the MHSWs saw social work as indefinable; operating in liminal spaces, and invisible to others. Next, there will a discussion of the isolation the MHSWs experienced in being seconded to Mental Health Trusts.

\section{Links with the Local Authority}

Several studies have identified that MHSWs retain only minimal links to the employing Local Authority. For example, the MHSWs in the study by Blinkhorn (2004) felt professionally isolated as they had been 'hived off' to the Trust without an effective link to the Local Authority. Bailey and Liyanage (2012) concluded that the MHSWs seconded to Mental Health Trusts in their study were 'disempowered' (p.1125) and have been 'abandoned' by their Local Authority employers (p. 1124). Finally, Allen (2014 p.26) found 'many examples of social work staff in mental health services who lack senior representation and voice and who cannot then get strategically important messages to the top table'.

All of the MHSWs interviewed for this research project who were seconded to Health Trusts remained employed by the Local Authority. This could be problematic. For example, Nell described the dual pressures of being employed by the Local Authority but working in the Health Trust as being 'Between a rock and a hard place'. None of the MHSWs seconded to a Trust described having strong links with the Local Authority. Andrew, for example, described having 'very small links':

Andrew: [pause] very small links. We've drifted right over to the Trust now. We are firmly seated within the Trust umm I always just feel that [name of Local Authority] pay my wages and that's it.

Using evocative language, Andrew describes how the MHSWs have 'drifted' away from the Local Authority to become 'firmly seated' in the Health Trust. For Andrew, the role of the Local Authority is reduced to simply paying wages.

Like Andrew, Cath uses language about "movement". She describes the Local Authority and Health Trust as initially moving 'separately but along the same path'. However, once the Local Authority manager left, no-one was recruited to the post even though having links with a manager from the Local Authority was originally built into the management structure: 
Cath: We had a local authority manager and I think that we felt more, that we always knew what was happening within the local authority and that we moved separately but along the same path. Now I think we feel that we are here somewhere umm and trying to keep those links. Particularly around mental capacity and safeguarding saying that we need to link with you more closely because we sort of need to follow your path and not be separate to it. Because we've not got a local authority manager now. We are totally managed by health. We don't attend team meetings for the local authority so that things that affect services in the local authority that we should be knowing about, we're not.

Cath uses two curt sentences to narrate the change in the management structure ['Because we've not got a local authority manager now. We are totally managed by health']. This means that the MHSWs in the Mental Health Trust no longer have any links with the Local Authority and so are not kept up to date with crucial matters such as safeguarding and mental capacity. Thus, like the MHSWs in previous studies, the social workers felt very isolated from their Local Authority employers. The finding from the study that the MHSWs had difficulties in making social work visible when isolated in a Mental Health Trust will now be explored.

\section{Making social work visible when isolated in a Mental Health Trust}

The majority of the MHSWs interviewed only had one or two social work colleagues in the Mental Health Trust. Instead, their colleagues were health professionals such as nurses, doctors, psychologists, and occupational therapists. Moreover, even if there were other social workers in the team, this did not automatically mean that the other social worker was a 'bona-fide' member (Garfinkel, 1967). For example, there was only one other social worker in the team where Nell was based:

Nell: Yeah and in this team because I'm the only well there is another social worker but she's employed by [the health trust] and so her training and her she's not an AMHP you know she's very much a nurse with a social work body [laughs]

Nell begins by stating that she is the only social worker in the team, but then corrects herself as signalled by the disfluency marker 'well'. Nell distinguishes herself from the other social worker in the team: whereas Nell is employed by the Local Authority and seconded to the Trust, the other social worker is employed directly by the Health Trust. The other social 
worker was also not qualified as an AMHP. Nell depicts this social worker as not a 'real' social worker but as a 'nurse with a social work body'. Although this is a humorous phrase and Nell laughs, it is not a laughable but is 'troubles talk' (Jefferson, 1984) and I do not respond by laughing (see Morriss, 2015c).

Next, I asked Nell if she thought that she brought anything distinctive to the team:

Nell: Oh yeah I think so. I think it would be a loss not to have social work qualified people in a team because you're going in to people's homes all the time and you see and pick up stuff that nurses don't seem to ummm [pause] they see it but they don't seem to recognise the umm possible effects or repercussions or, you know.

In an interesting reply in relation to visibility, Nell begins by stating that social workers have the ability to 'see' elements of service user's lives that Community Psychiatric Nurses (CPNs) do not seem to. She then reformulates this to say that the [community psychiatric] nurses 'see it' but do not seem to recognise the possible effects or repercussions of what they have seen. Nell then illustrates this claim with an 'atrocity story', a term created by Stimson and Webb (1975) in their study examining women patients' retrospective accounts of their contact with the medical profession. The patients told atrocity stories about doctors to each other during group discussions or in informal conversations observed by Stimson and Webb. The stories were told as eye witness accounts and had a dramatic quality. Stimson and Webb $(1975$, p.107) concluded that the stories were a way in which the patients could redress the inequalities in their relationships with the doctors. In the wider study, the MHSWs all told atrocity stories about CPNs (see Morriss, 2015d).

Here, Nell tells an atrocity story about the differences between home visits by MHSWs and CPNs:

Nell: You go round there and umm "how's your mood? Have you had any self-harm thoughts today?" you know, and then you go off again and go on to the next person and the fact that they're living in a cold flat because the central heating isn't working, the boiler broke down two years ago and has never been fixed you know, these things just just sail over people's heads just. I think how can you be comfortable in your own home or how can you even start to get happy or get out of 
depression if you've got no heating, no hot water, so how you going to clean yourself? And they say "oh they're dirty". I think of course they're dirty. They're freezing cold. I wouldn't take my clothes off and have a wash if I was cold [laughs] and nowhere to dry their clothes if they did wash it [pause] And the effect on someone's mental state or their mental health, their mood, their depression, it's not [pause] it's like they don't tie up the two things. It's very frustrating.

In this story, Nell is contrasting the differing perspectives of CPNs and MHSWs, with only the social workers being able to see the effects of the social circumstances that people are living in. Nell depicts social workers as having the ability to see a situation in its entirety in contrast to the CPNs where 'these things just just sail over people's heads'. In the story, the social worker was able to make the connection between inadequate housing and the impact on mental health; in contrast, the CPN cannot 'tie up the two things'. Nell uses reported speech to portray the CPN as only able to see that the service user is physically 'dirty'; the phrase attributed to the nurse presents them as somewhat appalled. In contrast, Nell presents herself as aligned with the service user and able to see why s/he is not able to have a wash or wash their clothes.

Through this story, Nell is claiming that only social workers are able to achieve an accurate and complete understanding of the situation. In contrast, CPNs are presented as having a narrow focus solely on symptoms of mental illness. Thus, Nell is contrasting the social perspective with the medical model. The coda to her reply provides a summary of the stance she is taking: it is 'very frustrating' being the only (real) social worker in a team of health professionals.

In another atrocity story, Eva also spoke about the differences in what CPNs and MHSWs 'look at':

Eva: We probably spent less time talking to people about their symptoms and that sort of thing. We look at different things. I mean we do, it is important but certainly not. I mean I've been out on assessments with nurses and who sit there and say to people "so, do you hear voices? Are you thoughts racing?" and the person is sitting there going "no, no, no" and you're sitting there thinking "they're obviously mad aren't they?" and the nurse comes away and goes "well, they're fine" and they're 
not are they? [laughs] But it's very [pause] you know. It's very medical. The guy was knocking his house down so it was obvious to me but the nurse didn't seem to notice that.

Again, in this story the social worker is portrayed as having a full picture of the situation compared to the much more limited view of the CPN. It was 'obvious' to Eva but the CPN 'didn't seem to notice' that the 'guy was knocking his house down'. The use of such a dramatic example, another 'extreme case formulation', displays the degree of just how limited the CPN's view of the situation was. The use of reported speech in an interaction and the laughter contributes to the sense of immediacy and drama of the atrocity story. The CPN is 'very medical' and only concentrates on the symptoms of mental distress ['"so, do you hear voices? Are you thoughts racing?"']. This limited medical view ['“well, they're fine"'] is contrasted with that of the social worker who is the only person who is able to see the reality of the situation ['they're obviously mad aren't they']. Here, the repeat of the word 'obviously' is used to 'authorise' the version (Smith, 1978). In effect, Eva contends that an accurate picture of what is happening can only be obtained through the social work perspective.

Thus, in the atrocity stories told by Nell and Eva, MHSWs are depicted as able to see something that is invisible to the nurses. Once more this aligns with Pithouse's claim that social work is invisible and cannot be seen by others. In the stories, even though the MHSWs and nurses are both in exactly the same situation, the true circumstances are only visible to the social worker. The work of Goodwin (1994) on 'professional vision' is especially relevant here. Using an ethnomethodological approach, Goodwin argued that occupational specialists develop a distinctive vision; socially organized ways of seeing and understanding events. He concluded that the ability to see relevant entities is situated within a community of competent practitioners; with different professions having the power to legitimately see, constitute, and articulate alternative kinds of events. Hence, whereas the social workers in Pithouse's study had a 'shared frame of reference' with their social work colleagues and thus were able make social work visible in their talk, here the MHSWs see different features from their health co-workers in the same situation. 
The final part of the paper will explore supervision. Significantly, for Pithouse, supervision is where social work is made visible.

\section{Making social work visible: social work supervision}

In his report of the Inquiry into the death of Victoria Climbié, Lord Laming (2003 p.12) identified supervision as 'the cornerstone of good social work practice'. It is through social work supervision that social workers receive emotional support and reflect upon their practice. Beddoe $(2015$, p.151) shows how supervision is 'so embedded in social work that it forms part of the language landscape wherever it is practised' and is frequently presented as being a 'universal artefact' of social work. Moreover, it is an important alternative to the managerialist approach (Carpenter et al., 2012) in which supervision is focused on efficiency, accountability and worker performance (Noble and Irwin, 2009). Pithouse concluded that supervision is crucial in social work as it is where social work is made visible:

It is here in the supervisory encounter that work and worker are 'seen' in mundane occupational talk steeped in the processes of social organisation. It is here that for all intents and purposes work is made visible and accomplished as a routine orderly event. (Pithouse, 1984 p.15)

Thus, in Pithouse's study, social work is accomplished and made visible in supervision through the talk-in-interaction between the social worker and their social work supervisor. It is through 'telling the case' (Pithouse, 1984 p.371) in supervision that the social worker accomplishes his or her social work identity, as well as the identity of the service user. Work can only be made 'visible' through shared occupational talk where the social worker successfully accomplishes 'doing being' (Sacks, 1992) a social worker. It is in supervision, then, that the social worker is recognised as being a 'cultural colleague' (Garfinkel, 1967 p.11). Here invisible practice is evaluated in a 'simultaneous exhibition of both worker and work' (Pithouse, 1998 p.10).

The children and family social workers in Pithouse's study were all supervised by social work managers. However, in being seconded to Mental Health Trusts, MHSWs may or may not have a manager who is from a social work background. This section will examine talk-aboutsupervision from three interviews. The first extract about supervision is from an interview 
with a social worker I have called Rose. Rose has just explained that she has worked in two mental health teams before her present position. I ask:

Lisa: And what about in the teams, did you have a social work manager in both? Rose: No in [name] I had a nurse as a supervisor and I found that difficult actually. I found it very prescriptive umm I don't know if it's to do with the profession or the personality of the supervisor but I found it was very much like doing a shopping list I thought. Not very reflective.

Rose describes how she found it difficult having supervision with a nurse. Although Rose states that the approach to supervision could stem from the personality of the individual nurse rather than nursing as a profession, she describes the pragmatic approach taken in somewhat derogatory terms. In contrast, social work supervision is 'reflective'. Social work supervision is implicitly associated with 'reflectiveness'. For example, Beddoe (2015 p.151) argues that supervision is 'held to be a fundamental component of professional development for social workers and generally thought to provide a major medium for facilitating ongoing reflective practice and learning'. The need for social work supervision to provide opportunities for critical reflection is mentioned several times in 'The Standards for employers of social workers in England' (2014). In a final example, point 8 of the Knowledge and Skills Statement for Social Workers in Adult Services (2015) is titled: 'Supervision, critical reflection and analysis'. Rose continues:

Rose: It was very much "what's happening with this?" very pragmatic, looking at the practical rather than anything about what's going on or what's the dynamics of the situation or anything.

Here Rose directly contrasts supervision by a nurse with social work supervision. Again, Rose presents supervision with a nurse as 'very pragmatic' and 'looking at the practical'; in contrast with social work supervision which is 'about what's going on' and 'the dynamics of the situation'. In other words, Rose is depicting supervision with the nurse in terms of the efficiency, accountability and worker performance described earlier; whereas, social work supervision is about reflection. Again, the use of reported speech works to support the contrast structure. The interview continues with my asking:

Lisa: And did you find that frustrating? 
Rose: Yes I did. Sometimes I'd think I'm fed up of talking: "I may as well just fax this over to you" you know, write one sentence about everyone [both laugh] "he's going to a daycentre she's going to a benefits assessment" yeah.

Here my question that this type of 'pragmatic' supervision would be 'frustrating' for a social worker displays my shared social work background expectancies. In her reply, Rose again uses reported speech and humour to describe how supervision with a nurse is so prescriptive that it could be done by fax. Thus, unlike the social workers in Pithouse's (1984) study supervised by social work managers, Rose is not able to make social work visible in supervision with the nurse. The nurse does not share the same occupational rhetoric and so Rose cannot accomplish a social work identity through their mundane institutional talk. Significantly, in direct contrast, within the interview interaction we do share the same occupational rhetoric and our shared laughter contributes to our ongoing accomplishment of 'doing being' social workers (Morriss, 2015c).

The second interview extract about supervision comes from the interview with Grace. Grace had been talking about her first job as a qualified social worker when she had a 'terrible' nurse manager.

Grace: Looking back and I think again looking at [pause] what I do now is [pause] I didn't have a lot of supervision. We weren't linked in with any other social workers. We weren't linked in we were in the attic of a big old school building so we were the weird relative in the attic so you never saw anyone. So I was really isolated. I wasn't an AMHP so I wasn't going to - well, ASW back then - umm and I just didn't get to see anyone at all. So I didn't get any career I asked for a career umm discussion and didn't get anywhere. Umm so never really have anyone leading me along really at all so it was really isolating. Horrible.

Lisa: Yeah and how did you maintain your social work identity during that time?

Grace: I clung on to the values. I clung on to an idea of what I thought a social work role would be and I carved it out.

Through this story, Grace described not having social work supervision as leaving her feeling 'really isolated'. Her description of the two social workers as being the 'weird relative in the 
attic' adds a dramaturgical dimension to the story, echoing the character of Mrs Rochester in 'Jane Eyre'. It places Grace and the other social worker as outsiders in the team. In addition, the allusion to mental distress is apt when the building contains a mental health team. By mentioning that she was not an AMHP or Approved Social Worker (ASW), Grace is alluding to our shared knowledge that if she had been she would have been able to access peer supervision. As well as the lack of social work supervision leading to isolation, Grace also presents supervision as strongly associated with professional and personal development, both of which suffered during this time.

In the coda to the story, Grace reiterates that the lack of supervision 'was really isolating. Horrible' thus ensuring that I had fully grasped the point that the story has served to illustrate. My response demonstrates my understanding through my affirmation and my question about social work identity. The question displays my assumption that having social work supervision is essential to making social work visible and accomplished as a routine orderly event (Pithouse, 1984 p.15). Grace's response displays the tacit assumption that maintaining a social work identity is implicitly bound with social work values. The phrase 'I clung on' is repeated twice and is evocative of the phrase 'I clung on for dear life' suggesting an urgency or desperation. There is also a balance in the beginning and end of this answer ['I clung on... and I carved it out'] which adds depth to the words. Here Grace accomplishes a sense of being proactive and assertive; a significant theme in all of the interviews (see Morriss, 2014).

These two extracts have shown how the MHSWs were unable to make social work visible in supervision as they did not have social work supervisors. The emotional impact of this was also apparent; the MHSWs were left feeling frustrated and isolated. The final section of the paper will explore an unexpected outcome of the research process: the notion of the research interview as surrogate supervision.

\section{The research interview as surrogate supervision}

The final extract in this discussion about supervision is from the very end of the interview with Paul. I had finished asking all my questions and ask Paul if he would like to add anything. 
Lisa: That's brilliant thank you. Is there anything that you wanted to add? Anything that you think I haven't covered?

Paul: No I think we're covered quite a lot [both laugh]. No it's good. I think in itself, you know, being interviewed it's nice just to get away from the office and the phones ringing and the questions being asked and just talk about my experiences and having you to facilitate that in itself is as good as a supervision... is kind of is a good opportunity to talk about your work is quite beneficial to your own well-being because you're talking to someone independent, impartial, objective, confidential and it's going towards some research study which is good in itself. I feel better just for talking so it's good so that's mutually beneficial [both laugh]

Here Paul makes a link between the interview and supervision: 'being interviewed... in itself is as good as a supervision'. Paul talks about taking time from the demands of the office to talk about his 'experiences' in the interview-interaction as 'beneficial' to his own 'wellbeing'. In this way the interview-interaction can be seen as mirroring one of the most fundamental components of supervision identified earlier: the opportunity to reflect.

Paul was the only social worker who explicitly made this link - and it is not something that I had considered before. However, many of the social workers spoke of the difficulties and dilemmas that they had experienced. One social worker, for example, told me that three people on his caseload had recently died in quick succession. Crucially, in Pithouse's terms, we had a shared frame of reference and so were able to make social work visible through our talk.

\section{Limitations}

The small sample size is the main limitation of the paper. Seventeen MHSWs were interviewed for the wider study but four were not seconded to a Mental Health Trust. The focus of narrative research is on in-depth qualitative interviews with a smaller group of participants which are then analysed in detail. Of course, it may be that the MHSWs who chose to be involved in the study had stronger views on being seconded to Mental Health Trusts. Due to space constraints, it has not been possible to provide longer extracts which would display the interview interactions in more detail. However, in line with the advice of 
Seale (1999) and Riessman (2007), a full account of the methodological decisions made during the project is explicated in the account of the wider study (see Morriss, 2014).

\section{Conclusion}

The focus of the paper has been to demonstrate the (in)visibility of mental health social work. The MHSWs were isolated within Health Trusts with minimal links to their Local Authority employers. The MHSWs struggled to articulate and define social work. Instead, social work was depicted as being indefinable, involving working in liminal spaces and as filling in the gaps left by other professions. Furthermore, they were unable to make social work visible as social work is not 'seen' by the other non-social work members of the mental health team. Finally, the MHSWs were unable to make social visible through supervision if they did not have a social work manager. An unexpected outcome of the research was the notion of the research interview as surrogate supervision as we both shared the same social work frame of reference.

These findings show how social work is not accomplished as a routine orderly event in mental health teams and so remains invisible (Pithouse, 1984 p.15). However, one way that social work is made visible has been touched on; Grace alluded to the idea of peer supervision, particularly in relation to AMHP work. However, this is dependent on the availability of other social workers and making personal contacts rather than being built into the structure of the Health Trust. Allen (2014 p.23) reports that some partnership arrangements between Mental Health Trusts and Local Authorities have recently dissolved due to the lack of strong operational management and locally available professional leadership of social work practice. In these cases, MHSWs have returned to their Local Authority employers.

The emotional labour of mental health social workers undertaking AMHP work is immense and particularly draining (Gregor, 2010; Morriss, 2015a). Thus, it is imperative that these social workers are supported in their work. The availability of support should not be ad hoc and dependent on individual circumstances; rather it is crucial that this is fundamental to the management structures within the Mental Health Trust.

\section{Acknowledgements}


The research was funded by a Ph.D. studentship awarded by the Economic and Social Research Council. The author would like to thank Andy Pithouse for his inspiring work and his encouragement. Finally, thank you to Jadwiga Leigh for being my academic partner in crime.

\section{References}

Allen, R. (2014). The role of the social worker in adult mental health services. The College of Social Work.

Bailey, D. and Liyanage, L. (2012). The Role of the Mental Health Social Worker: Political Pawns in the Reconfiguration of Adult Health and Social Care. British Journal of Social Work, 42(6), 1113-1131.

Blinkhorn, M. (2004). Social Worker: Leading roles in mental health. Durham: Northern Centre for Mental Health.

Beddoe, L. (2015). Supervision and developing the profession: one supervision or many? China Journal of Social Work, 8(2), 150-163.

Carpenter, J., Webb, C., Bostock, L. and Coomber, C. (2012). Effective supervision in social work and social care. London: Social Care Institute for Excellence.

Department of Health. (2015). Knowledge and Skills Statement for Social Workers in Adult Services. London: Department of Health.

Garfinkel, H. (1967). Studies in Ethnomethodology. Englewood Cliffs, N.J.: Prentice-Hall. Goodwin, C. (1994). Professional Vision. American Anthropologist, 96(3), 606-633.

Gregor, C. (2010). Unconscious aspects of statutory mental health social work: Emotional labour and the Approved Mental Health Professional. Journal of Social Work Practice, 24(4), 429-443.

Holt E. and Clift, R. (2007). Reporting talk: reported speech in interaction. Cambridge: Cambridge University Press.

Hughes, E.C. (1971). The sociological eye: Selected papers. Chicago: Aldine-Atherton. 
Jefferson, G. (1985). On the organization of laughter in talk about troubles. In J.M. Maxwell and J. Heritage (Eds), Structures of social action: Studies in conversation analysis (pp.346369). Cambridge: Cambridge University Press.

Laming, H. (2003). Report into the Inquiry into the death of Victoria Climbié. Department of Education.

Morriss, L. (2014). Accomplishing social work identity in interprofessional mental health teams following the implementation of the Mental Health Act 2007. Unpublished doctoral thesis, University of Salford, UK.

Morriss, L. (2015a). Dirty secrets and being 'strange': using ethnomethodology to move beyond familiarity. Qualitative Research. Published online before print: September 3, 2015.

Morriss, L. (2015b). AMHP work: dirty or prestigious? Dirty work designations and the Approved Mental Health Professional. British Journal of Social Work. Published online before print: February 26, 2015.

Morriss, L. (2015c). Doing non-seriousness: Accomplishing social work identity through humour and laughter. Qualitative Social Work, 14 (3): 307-320.

Morriss, L. (2015d). Nut clusters and crisps: Atrocity stories and co-narration in interviews with Approved Mental Health Professionals. Sociology of Health and IIIness. 37(7): 10721085.

Noble, C. and Irwin, J. (2009). Social Work Supervision: An Exploration of the Current Challenges in a Rapidly Changing Social, Economic and Political Environment. Journal of Social Work, 9(3), 345-358.

Pithouse, A. (1984). Social work: The social organisation of an invisible trade. (Unpublished PhD thesis), University College, Cardiff.

Pithouse, A. (1998). Social Work: The social organisation of an invisible trade. Aldershot: Avebury Gower.

Pomerantz, A.M. (1986). Extreme case formulations: a new way of legitimating claims. Human Studies, 9, 219-230. 
Riessman, C.K. (2007). Narrative Methods for the Human Sciences. Thousand Oaks, C.A.: Sage.

Sacks, H. (1992). Lectures on Conversation. Oxford: Basil Blackwell.

Seale, C. (1999). The Quality of Qualitative Research. London: Sage.

Smith, D. (1978). K is mentally ill: the anatomy of a factual account. Sociology, 12, 23-53.

Social Work Reform partners. (2014). The Standards for employers of Social Workers in England. Local Government Association.

Stimson, G. and Webb, B. (1975). Going to see the doctor: The consultation process in General Practice. London and Boston: Routledge and Kegan Paul. 